\title{
التصور التداولي للمقام في مدونات القرن الرابه الهجري النقدية
}

أ.د بشرى موسى صالح/ قسم اللغة العربية / كلية التربية / الجامعة المستنصرية م.مم صيدر إسما عيل عسكر / قسم اللغة العربية / كلية التربية / الجامعة المستنـصرية

\section{ABSTRACT}

Pragmatic perception of the context in the codes of the fourth century $\mathrm{AH}$

This research is trying to take off from the idea that the place is an important focus of the curriculum pragmatic axes, can benefit from the disclosure of critical perception in the codes of the fourth century $\mathrm{AH}$, based on our conviction that the recruitment method pragmatic in the study of codes of cash that will lift the lesson cash heritage that can cause a change in our view of the traditional critical levels to our heritage

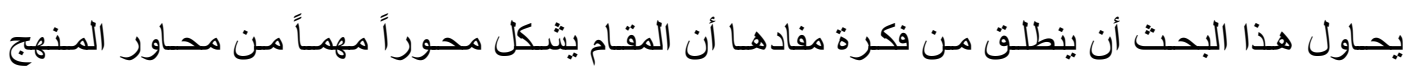
التداولي، يمكن الإفادة منه في الكثف عن التصور النقدي في مدونات القرن الرابع الهجري، انطلاقاً من قناعتنا أن توظيف المنهج التداولي في دراسة المدونات النقدية من شأنه أن برتقي بالدرس النقدي التراني إلى مستويات كفيلة بإحداث تغيير في نظرتتا التقليدية لتر اثنا النقدي.

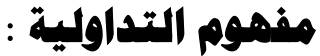

يقترح الدكتور طه عبد الرحمن المنهج التداولي في تقويم التراث، ودر استه بوصفه منهجاً متكاملاً يتميز بدعامة أساسية تستند إليها نظرتنا في تكامل التراث أطلاق عليها (دعوى التداول الأصلي)، ومضمون هذه الدعوى هو الاعتماد على المنهج التداولي (لا سبيل إلى تقويم التراث مـا لم يحصل الاستتاد إلى مجـال تداولي متميز عن غيره من المجالات بأوصاف خاصة ومنضبطة بقو اعد محددة يؤدي الإخلال بها إلى آفات تضر بهذه الممارسـة)(') وإن الحديث عن التداولية من حيث النشأة و المفاهيم يفرض الاشـارة الى العلاقات القائمة بينها وبين الحقول المختلفة؛ لأنها تشي بانتمائها الى حقول مفاهيمية تضم مستويات متداخلة تمثل بذللك حلقة وصل مهمـة بين حقول معرفيـة عديدة منهـا: الفلسفة التحليليـة، علم النفس المعرفي، علوم التواصل، اللسانيات، علوم اللغة. (؟)

التداولية لغة : إن الجذر اللغوي (للتداولية) هو الفعل الثثلاثي (دَوَلَ)، الذَالُُ والوَاوُ و اللامُ، يدل على تحول الثَسيء من مكان إلى آخر، حيث قال أهل اللغة: إندَالُ القوم، إذا تحولوا من مكان إلى مكان، ومن هذا البـاب تَدَاولَ

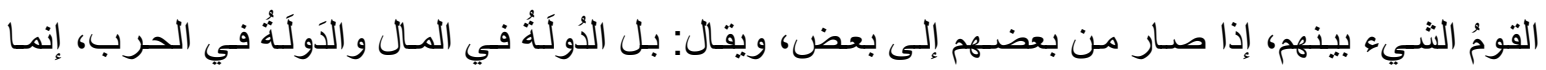

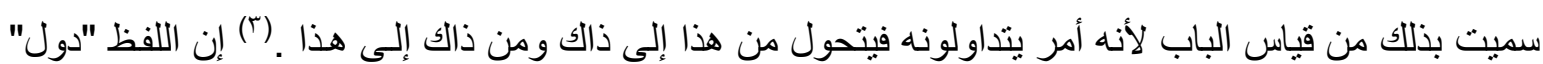
ورد في المعاجم العربية والقرآن الكريم بمعنى الانتقال والتحول، سواء في حال أو مكان أو من شخص إلى هـ آخر مما يقتضي وجود أكثر من طرف واحد في هذا الفعل. 


\section{التداولية اصطلاحك:}

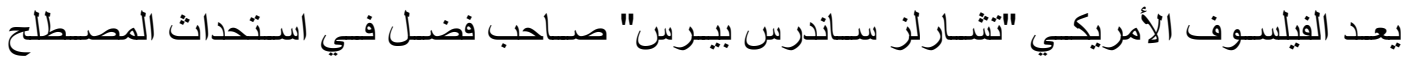
في حين يرجع أول استعمال لهذا الهصطلح إلى الفيلسوف: والسيميائي الأمريكي" تثـارلز

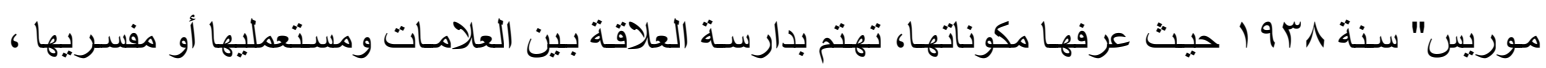

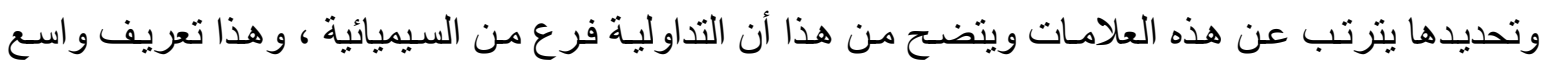
يتعدى المجال اللساني إلى السيميائي ـ (4) ويعد الدكتور طه عبد الرحمان أول باحت عربي استعمل مصطلح

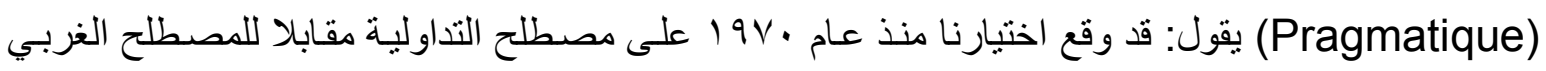

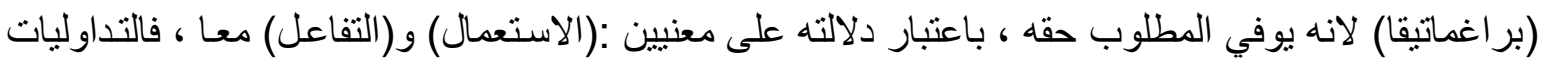

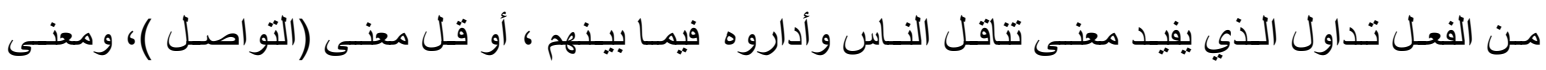

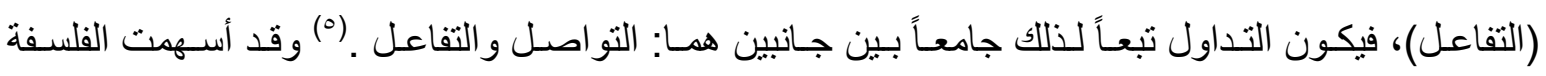

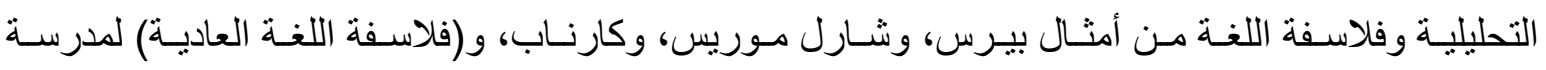

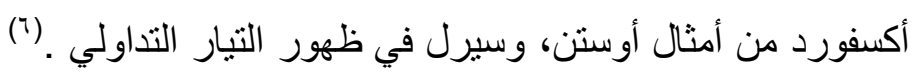

وقد أعادت دراسـات هؤلاء للغذة ديناميتها بثكل جديد بعيدا عن التحليل الفيلولوجي أو البنيوي

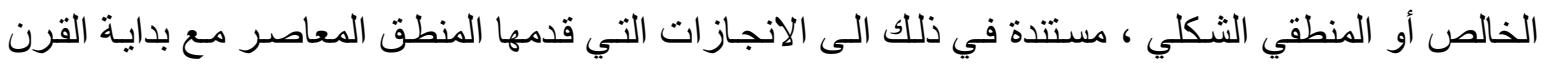

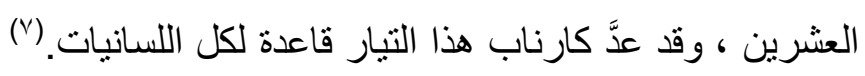

تُعنى التداولية بوصف العلاقات القائمة بين المرسل و المرسل اليه في اطار عملية التواصل ، كمـا

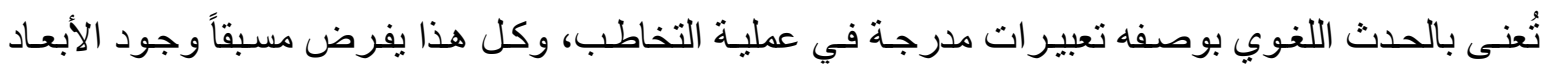

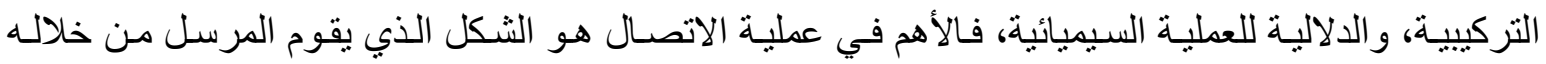

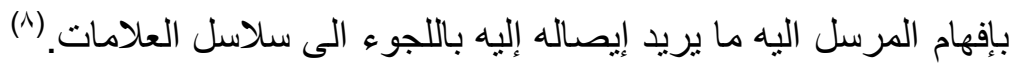

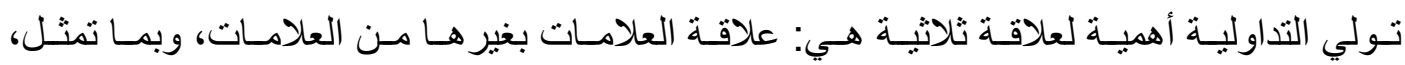

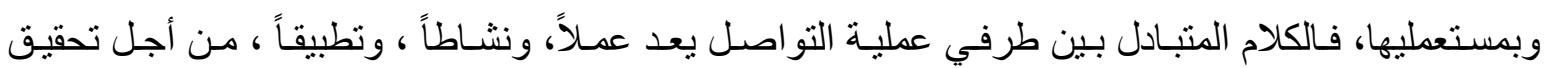

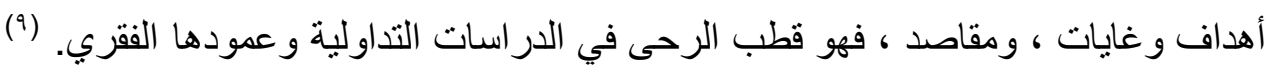
لقد اكتسب مصطلح التناولية دلالات عديدة ، ويتضح ذلك من خلال تقري سياقات هذا المصطلح

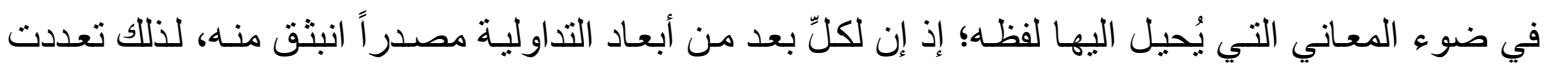
تعريفات التداولية، وكان لهذا التعدد أثر في ترجمة التداولية إلى اللغة العربية ، فقد ترجمت إلى الذئة الذرائعية،

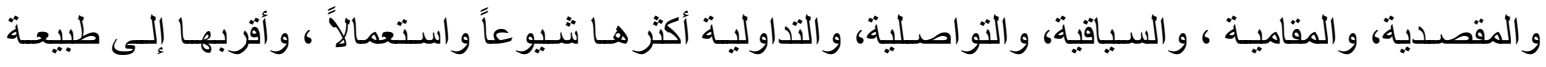

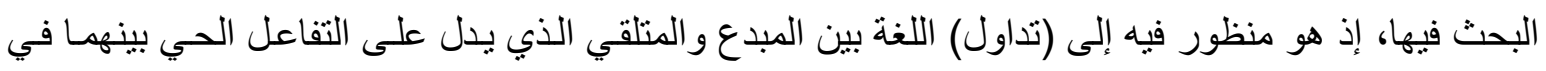

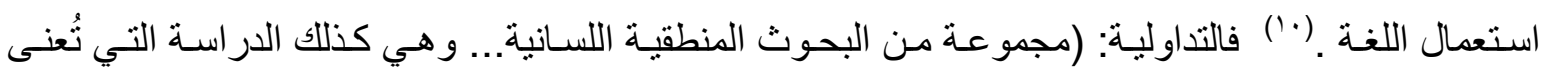

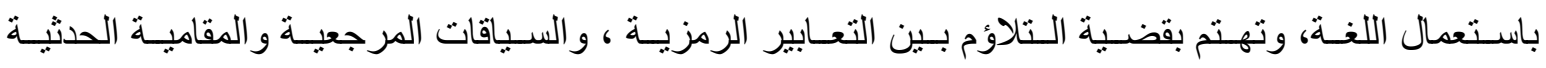

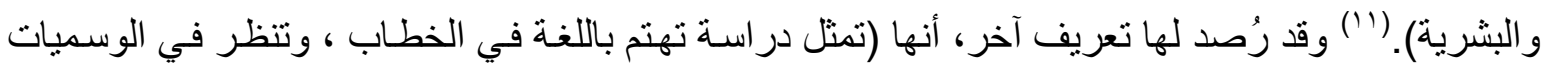


الخاص به ، قصد تأكيد طابعه التخاطبي ) .(r')، وهي (الدراسة أو التخصص الذي يندرج ضمن اللسـيات ،

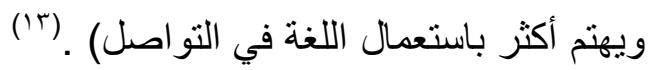

فالتداوليـة منهج جديد في حقل الدراسـات النقديـة تهنت بالانسـاق التواصلية للخطـاب، ومن هنـا فإن أشمل تعريف للتداولية هو ما استخلصه الدكتور محمود أحمد نحلة من تعريف (موريس) الذي يشكل الأصل في كل الدراسات التي جاءت بعده ، و هو أن التداولية هي (دراسـة اللغة في الاستعمال، أو في التواصل ،لأنـه يُشـير إلىى المعنى ليس شـيئاً متأصسلاً في الكلمـات وحدها ، و لا يـرتبط بـالمتكلم وحده ، و لا السـامع وحده، فصناعة المعنى تتمثل في تداول اللغنة بين المتكلم و السـامع في سباق محدد(مادي ، واجتمـاعي ، ولغوي)

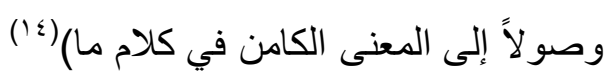

ومن خلال ما سبق من التعريفات نخلص إلى أن مصطلح التداولية يعنى بدر اسـة اللغـة في إطـار

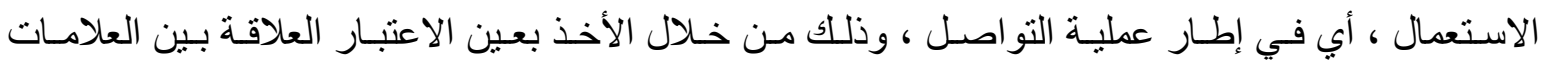
المتو اصل بها وبين مكونات العملية التواصلية .

\section{هفهوم التواصل التداولي:}

و التو اصل هو تبادل أدلة بين ذات مرسلة وذات مستقبلة ، حيث تنطلق الرسالة من الذات الأولى نحو الذات الأخرى، وتقتضي العملية جواباً ضمنياً أو صريحاً عمّا نتحدّث عنه ، الذي هو الأشياء والكائنات، أو بعبارة أثنمل موضو عات العالم ، ويتطلب نجاح هذه العملية اشتر الك المتكلم والمتلقي في السنن حتى ينت التو اصل و التفاهم على الوجه الأكمل كما أر اد له المجتمع اللغوي ، كمـا تقتضـي العملية قناة تنقل الرسـالة من

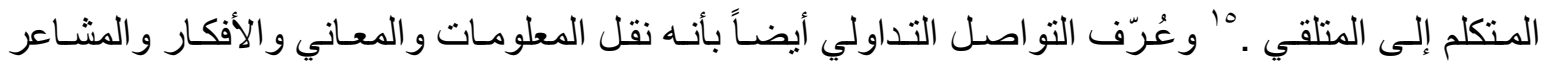
بواسطة العلامات و الإشار ات من مرسل إلى متلق ، عبر قناة ما ـ 17 هذا يعني أن هنالك ظو اهر لسـانية ، وخـار ج لسـنية (تداولية ) اجتماعية وثقافية وفكريـة التي تحكم إمكانية نقل الأفكار و المعلومـات بين ممثلي الخطـاب ، كمـا أن هاتـه الإمكانيـة تتم باللغـة المنطوقة ، كمـا تتم

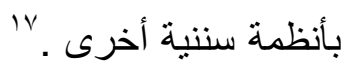
وللتو اصل تعريفـات متباينـة تبعـاً لتباين الإطـار المرجعي المستعمل ، فكل حقل معرفي يؤكد على عنصر من عناصر العملية التواصلية دون سواه ، فينظر إلى التواصل في ضوء مـا هو مشَغول بـه، وكل باحث ينظر إليه من الجهة التي تحقق الأهداف التي يسعى إلى تحقيقها ؛ لذلك جاءت التداولية لتحقق التكافؤ بين عناصـر التواصـل وتتـكل نسقه العـام بقصــ التفاعل ، و التـأثير المعرفي أو الوجداني بينهم، فالتو اصـل

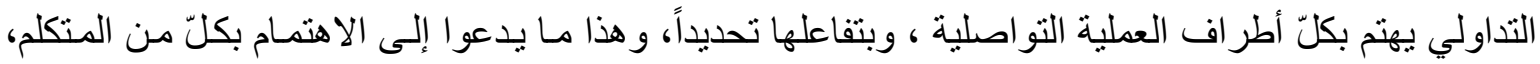
و المتلقي، و الخطاب، والسياق، و المقام الذي يتم فيـه التواصل، وبهذا الفهم يكون التو اصل نشـاطاً رئيساً يمنح اللغة طابعها التداولي. وتجدر الإشارة إلى أن مصطلح (تواصل) في حدِّ ذاته مـا هو إلاّ تحيين حداثي لمفهوم رجر اج يدخل في علاقة نر ادف و اشتر الك مع مجموعة من المصطلحات التي نشـاركه في الدلالـة سو اء من حيث الجذر اللغوي أو من حيث الحقل الدلالي وذلك مثل: التواصل، الإيصـال، الوصل، الإبـلاغ، الإخبار، 
التخاطب أو المخاطبة، التحاور أو المحاورة، إذ تستعمل هذه الكلمات في المجال الذي يفيد ربط علاقة معينة بين شيئين. 1 بائين

\section{مفهوم الإقام :}

إنّ النظر إلى التداولية بوصفها علماً يدرس تأثير المقام في معاني ملفوظات الأقوال ، فيشكّل المقام بهذا الوصف أهم المرتكز ات التي تقوم عليها عملية التواصل ، فهو نظـام لـه بنية من العناصر غير اللغويـة المرتبطة ارتباطاً وثثقاً بالنص الكلامي بهدف بلوغ المعنى المراد ـ(9') وبتعبير آخر هو مجموع الثروط التي ،

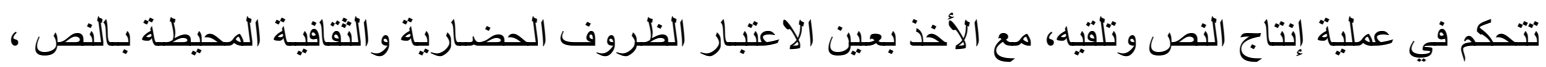

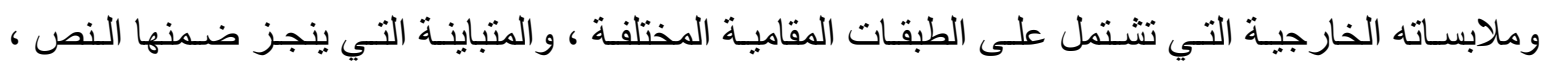
وتصلح لإحداث التأثير الذي يُنشده المبدع في موقف اتصالي محدّد .(r) فالمقام يفضي إلى بروز فكرة ربط المقال بالمقام وملاءمته لمقتضى الحسال من أجل تحقيق المقاصد ، الأمر الذي يجعل المقام يـذل في سياق التو اصلـ التداولي (بوصفه نسقاً مـن القيم والإجر اءات العمليـة

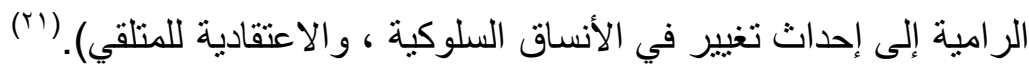
وربط الدكتور صـلاح فضـل بين التداوليـة بوصفها العلم الذي يُعنى بالعلاقـة بـين بنيـة النص ، و عناصر الموقف التو اصلي المرتبطة به بشكل منظم، ممـا يطلق عليه سياق النص، إذ ربط بين هذا المفهوم للتداوليـة، وفكرة (مقتضـى الحسال)، حيث قـال: (ويـأتي مفهوم التداوليـة هذا ليغطي بطريقـة منهجيـة منظمـة المسـاحة التي كـان يُشـار إليهـا في البلاغـة العربيـة القديمة بعبارة مقتضى الحسال، وهي التي أنتجـت المقولـة

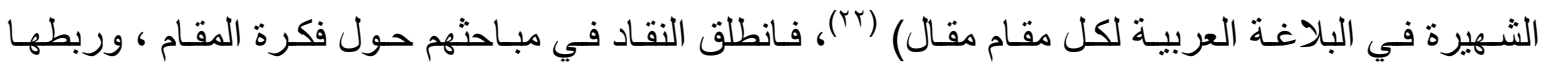

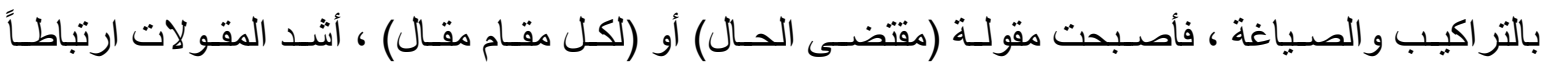

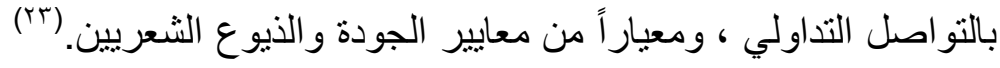
وقد جعل ابن طباطبا من موافقة الثـعر للحسال (المقام) التي ينشـأ قول الثـعر من أجلها سبباً من أسباب حسن الثعر وقبوله فيقول: (ولحسن الثعر وقبول الفهم إياه علة أخرى ، و هي مو افقته للحسال التي يُعد معناه لها ، كالمدح في حسال المفاخرة ، وحضور من يكبت بإنشـاده من الاعداء، ومن يُسر بـه من الاولياء،

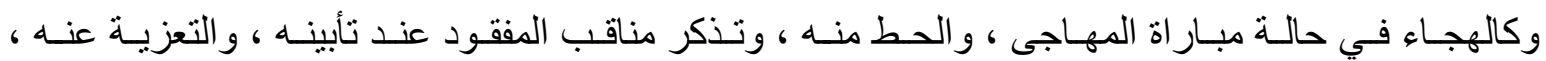
وكالاعتذار و التتصل من الذنب عند سلِّ سخيمة المجنى عليه ، المعتذر إليه ، وكالتحريض على التتال عند التقاء الاقر ان ، وطلب المغالبـة ، وكـالغزل و النسـيب عند شكوى العاثـق ، و اهتيـاج شـوقه وحنينـه الى مـن

يُشتير هذا النص إلى الوعي النقدي لابـن طباطبـا بمفهوم المقـام ، فـالر ابط بين عناصـر التواصل التداولي هو المقام الذي يحتم على المبدع أن يختار ألفاظه ، وتر اكيبه بمـا يناسب المضدمون من جهة ، وحسال المتلقي من جهة أخرى ، فلا يتحقق التأثثر (حسن الوقع) في المتلقي إلاّ إذا نمت الملاءمـة ، و الموافقة بين المعاني ومقاماتها مع الإلماع إلى ضرورة حسن الربط بين أطر اف العملية التواصلية . 
إن التواصل التداولي في تصور ابن طباطبـا يكمن في مر اعاة الاحو ال بين المتخـاطبين انطلاقاً من أن التداولية تهتم بجميع شـروط الخطاب ، وتعتمد أسلوباً في فهمهـ ، و إدر اكه بدر اسـة كيفيـة استعمال اللغـة، وشرح سياق الحال و المقام الذي يؤدي فيه المتخاطبون خطابهر ، ومن الاشتر اطات التي حرص ابن طباطبا على توجيه المبدع مر اعاة الشروط الاجتماعية في الثعر ، وتتجلى هذه المر اعاة في بناء النص بناءً ير اعي مقام المتلقي ويعني حسن ملاعمة المقال للمقام ، بوصفه معيار اً نقدياً يسـاعد على فهم النص، وتقدير نجاعته إذ يقوم الثناعر بمخاطبة ذات معينة مع مر اعاة ذوات أخر ، وفضلاً عن هذا يمكن أن تتم المر اعاة عن طريق تزويد المخاطبات الداخلية بمبدأ الإفادة الخارجية الذي يتحقق عن طريق مر اعاة المقامـات، لذلك بطالب ابن طباطبـا الثـاعر بمر اعـاة الظروف الماديـة والاجتماعيـة التي يتم في إطارهـا إنجـاز النص (مقتضى الحسال الخارجي)، وما يترتب عن ذلك من مخاطبة كل طبقة من الناس على وفق منزلتها الاجتماعية وحظها من

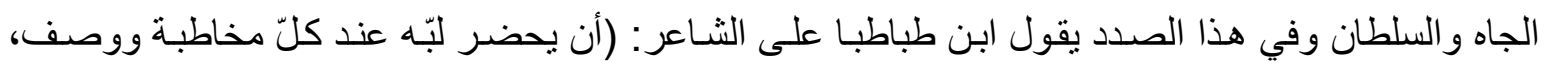
فيخاطب الملوك بما بيتحقونه من جليل المخاطبات، ويتوقى حطها عن مر اتبها ، أو أن يخلطها بالعامـة، كمـا يتوقى أن يرفع العامـة إلى درجات الملوك ويعد لكل معنى مـا يليق بـه، ولكل طبقة مـا يشـاكلها حتى تكون الاسـفادة مـن قولـه فـي وضـعه الكـلام مواضـعه أكثر مـن الاسـتفادة مـن قولـه في تحسـين نسـجه و إبداعـهـ

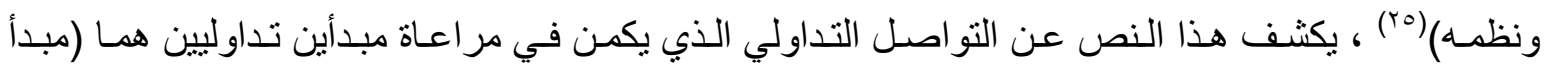
الملاءمة ، ومبدأ التأدب )(rr)، وهذان المبدآن التداوليان يحققان الربط الوثيق بين انسجام النص نظماً ونسجاً (المستوى الجمالي)، وبين حسال المخَاطَب (المستوى المقامي) للنص، إن هذا التو افق بتصـور ابن طباطبـا يحقق للنص شعريته ، ويكون الثناعر غاية في الابداع ، و إن الإخـلال بأي مستوى منهمـا يُفقد النص جماليته و وكانته، وقد جعل ابن طباطبا معيـار أ لكلِّ مستوى، فالمستوى الجمالي معياره القريحة التي ترتبط بالقدرة الابداعية للشـاعر، أو قدرته على التعبير الجمالي، ويتضح هذا المعيار في حديثه عن (الابيـات التي زادت قريحة قائليها على عقولهم)(YV)، ويعني بذذلك الأشـعار التي حققت المعيـار الجمالي؛ ولكنها أخلت بالمعيـار المقامي.

أما المستوى المقامي فمعياره العقل وقد ذكر ابن طباطبا أشعار اً كثيرة، تدل على ارتباط موافقة العقل بالمقام ، فكأن العقل عنده يوجهه صـاحبه إلى مر اعاة ظروف الواقع الخـارجي، وحسن الاستجابة لها، الأمر الذي يعني أن العقل بُمنل الثروط التداولية للقول الشعري. ومن مر اعاة مقام المتلقي، وتقدير مقامات الكلام ، وظروفه يُشير ابن طباطبا إلى أن يحترز المبدع في مقام كالمدح ، أو التهنئة بمناسبة سعيدة ، أو ما شابه ذلك ، من إيراد ألفاظ قد تفسد على المتلقي هذه الحالة

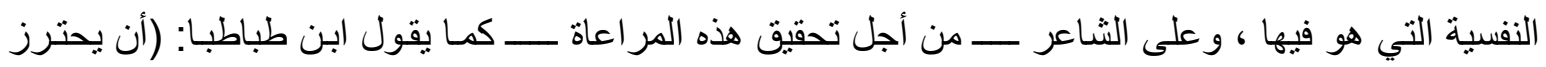
في أثـعاره، ومفتتح أقو الـه ممـا يُتطير بـه، أو يُستجفى من الكـلام و المخاطبات،كذكر البكاء، ووصف إقفار

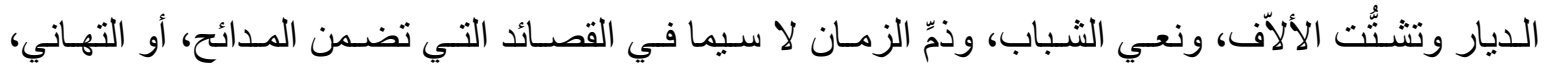
وتستعمل هذه المعاني في المراثي، ووصف الخطوب الحادثة ؛ فإن الكلام إذا كان مؤسساً على هذا المنال تطير منه سامعه)(^^) ، يريد ابن طباطبا في هذا النص أن يضع يد الثـاعر على الأشعار التي لم يراعِ فيها 
أصحابها اللياقة ولا الذوق الاجتماعي؛ وذلك ليحذر الوقوع فيها فقد جانب الأعثى الصواب في التعامل مـع

مقام الممدوح في قوله:(99)

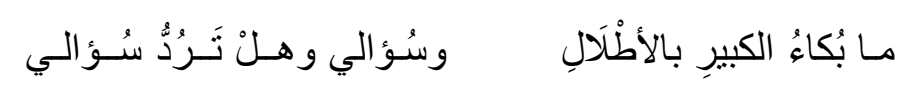

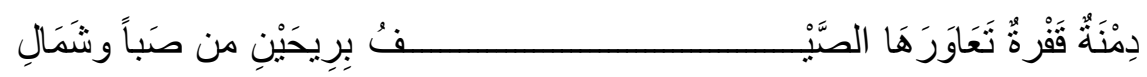

$$
\begin{aligned}
& \text { وأنكر عبد الملك بن مرون على ذي الرمة قوله : }
\end{aligned}
$$

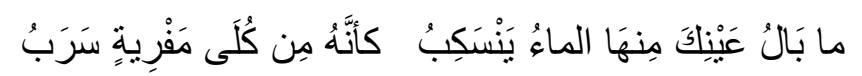

$$
\begin{aligned}
& \text { وقد أنكر الفضل بن بحيى البرمكي على أبي نواس قوله : }
\end{aligned}
$$

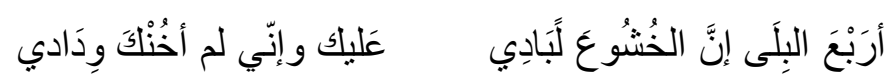

و هذه الأمثلة التي ذكرهـا ابن طباطبـا تمثل تطبيقات على توجهه النقدي في بيـان أهميـة المقام في

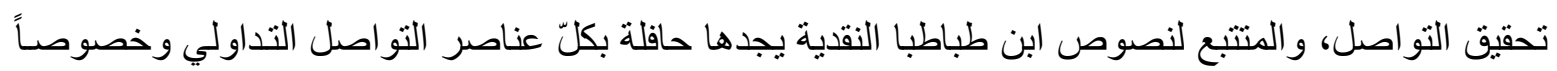
عنصر المقام.

و المقـام عند قدامـة بـن جعفر شـرط تـداولي يعنى بضـرورة موافقـة أفعـال القول لمقتضـى الحسال و الموقف الخاص به، إذ أفاد قدامة من مقولة عمر بن الخطاب في وصف شعر زهير بن أبي سلمى، إذ قال:

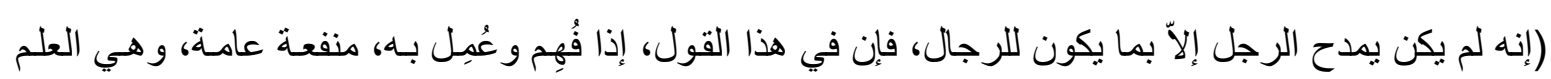

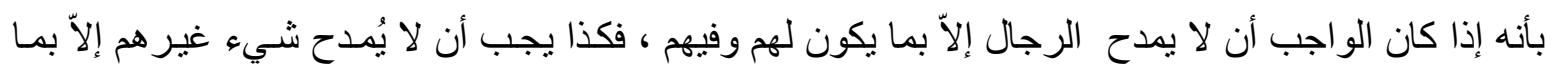

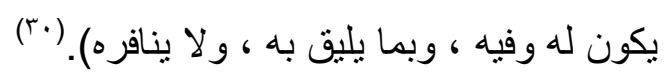

هذا النص يُشير إلى تقسيم المدح على أقسام يوزعها على الممدوحين من أصناف الناس بحسب مقامهم، ومكانتهم الاجتماعية (مدائح الرجال تنقسم أقساماً بحسب الممدوحين من أصناف الناس في الارتفاع و الاتضاع، وضروب الصناعات، والتبدّي و التحضر) ('ا"). هذا التقسيح للمدائح يدخل تحت مقولة (لكل مقام مقال)، إذ عمد قدامة إلى تحقيق شرط المقام في تداول المدائح هذا الثرط الذي يقضي بالتو افق بين بنية النص

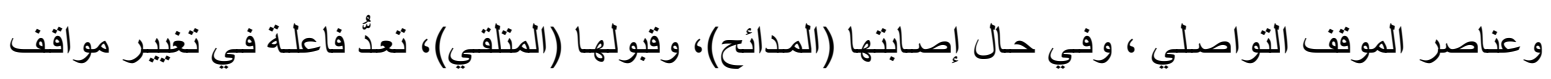
التو اصل.

ومن الأمنلة التي حققت التر ابط و الانسجام ، ومر اعاتها مقام المتلقي قول النابغـة الذُّبانيّ في مدح

(بr): النعمان بن المنذ

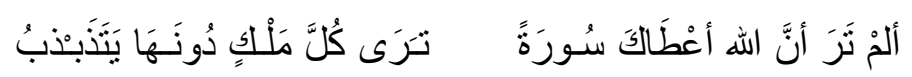

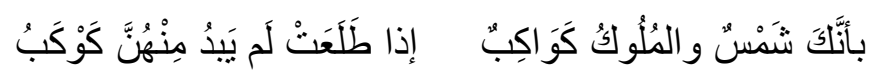

فقد أصاب الوجه المطلوب في وصف الملوك بتعبير قدامة . 
وربط النقاد عمود الثـعر بالمقام بوصفه المقاربـة التداوليـة الحاضـرة في كل الخطابـات النقيـة ،

فعناصر عمود الثـعر تمثل شروط تداولية المقام اهتدى إليها النقاد لضبط الاستعمال الثـعري في مبدأين :

الوقع و الإفهام . (r) (ب)

يمثل كتاب الموازنة تطبيقاً عملياً لعناصر عمود الثعر، إذ ربط الآمدي عناصره الفتية بواقع الحياة

العربيـة ، فالثـعر الجيد هو مـا جـاء موافقاً لطبقات المتلقين ، ومقامهم الاجتمـاعي، فيصسور الثـاعر مـا أراد التعبير عنه من المعاني تصوير اً مطابقاً لما عليه، فالوصف لا يأتي إلاّ لمطابقة الكلام لمقتضى الحال، و عليه أن يورد من المعاني اللائقة لذلك مقدار مـا يناسب طبع المخاطب، فمثناً إذا أراد الثـاعر أن يمدح أو يذم أو يهجو، فلكل معنى من هذه المعاني ألفاظ تشاكلها فتحسن فيها، وتقبح في غيرهـا ، ومن هنا يأتي القول بربط الكلام بالمقام ، أي وضـع الألفاظ في مو اضعها المناسبة لها مر اعياً حـال السـامع. ويرى الآمدي أن أبـا تمـام أخل في كثير من المواضع بشرط المقام حتى أشكل شعره ، وخالف العرف المستعمل في الوصف . . تشكل رؤيسة أبي هـلال للمقام من الملامـح المهـة في ربط البلاغة بالاتصـال في الدرس البلاغي و النقدي القديم، إذ وضع المتلقي ضمن دائرة التو اصل بوصفه العنصر الأساسي في فهم النص، لذللك يشكل المبدع نصه على وفق ثقافة المتلقي ولتوضيح فكرة المقام انطلق أبو هلال من أفكار بشر بن المعتمر الذبي يقول: (ينبغي أن تعرف أقدار المعاني ، فتو ازن بينها وبين أقدار المستمعين، وبين أقدار الحالات، فتجعل لكلِّ

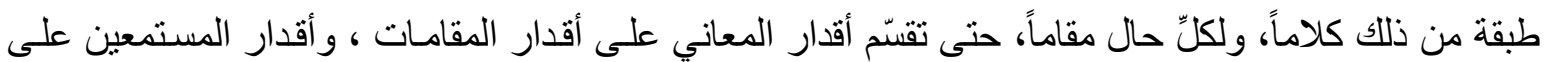

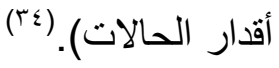

هذا النص يحدد العلاقة التواصلية بين المبدع ، والمتلقي، والسياق الذي يقدر فيه النص، إذ يركز النص على مبدأ المناسبة ، الذي يشكل المعيار الضابط في تعيين المقامات من جهة ، وضرورة انتقاء المعاني (المضمون) المناسبة التي تـلاءم المتلقي بحسب مـا تقضيه قدر اته، فتحقيق مبدأ المناسبة بين السياق ، ومـا يستدعيه حـال المتلقي ، فللسياق أثر مهم في ضبط التو اصل ، وتحقيق المنفعة من المتلقي وتجنب غضبه (و اعلم أن المنفعة مع مُو افقة الحال ، وما يجبُ لكلّ مقام من المقال ؛ فإن كنتَّ متكلماً، أو احتجتَّ إلى عمل خطبة لبعض من تَصلُحُح له الخُطب، أو قصيدة لبعض ما ير اد له القصيد ، فتخَطّ ألفاظ المتكلمين ، مثل الجسم

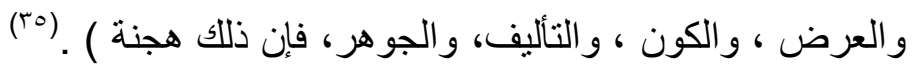
إن مر اعاة حال المتلقي في المجتمع العربي القديم هو واجب بغية استرضـائه لجلب خيره ، ودفع شره، لذلك يوظف المبدع تقنيات تداولية ترسيخاً للوظيفة الإفهاميـة التي تُعنى بها البلاغـة العربيـة ، فالمقام مقيد بمر اعاة الاحوال الاجتماعية التي يأتي على أساسها إنتاج النص . (بَّ) فالبليغ عند أبي هلال أن يكون(

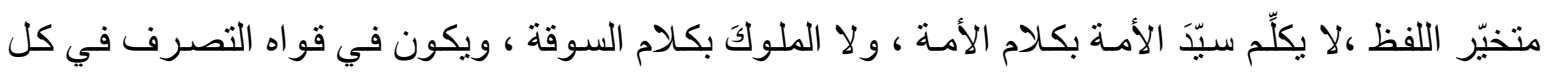

طبقة)( ملني

فـلا بـد للمتكلم أن ير اعي المقـام الاجتمـاعي للمتلقين حفاظـاً على ميثـاق التو اصل لتحقيـق الفائدة ،

و المنفعـة (و إذا كـان موضـوع الكـلام على الإفهام ، فالو اجب أن تقسّم طبقـات الكـلام على طبقـات النـاس ، 
فيخاطب السوقي بكلام السوقة ، والبدوي بكلام البدو، ولا يتجاوز بـه عمّا يعرفه إلى مـا لا يعرفه ، فتذهب

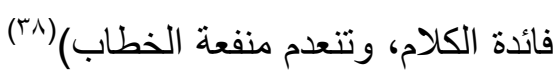

فالروابط بين المبدع، والمتلقي روابط قويـة ووثيقة ، فالمقام ليس مـادة لغويـة منفصلة عن مقامها ،

و لا عنصر اً يقع خارج المقال، وينفصل عنه، فهذا الأمر يعني استحالة الفصل بين المقال والمقام ، فـالمتكلم

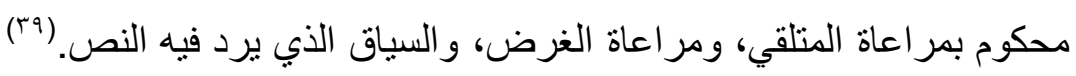

\section{هواهش البمث}

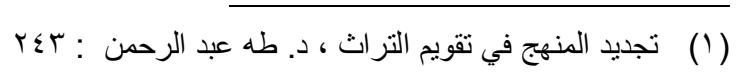

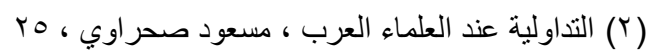

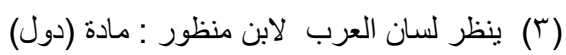

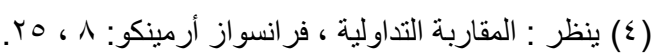

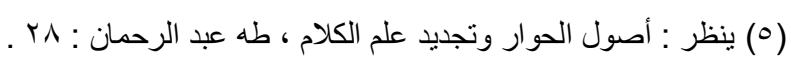

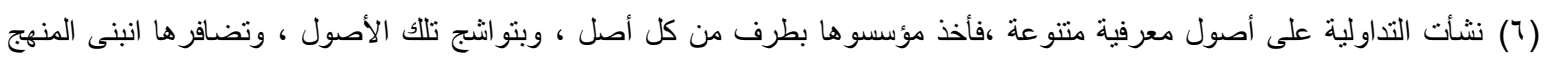

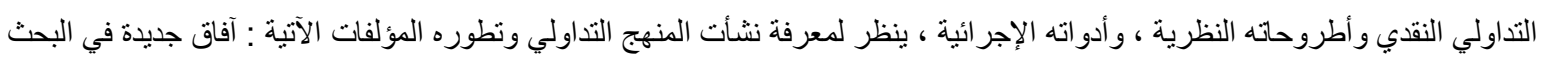

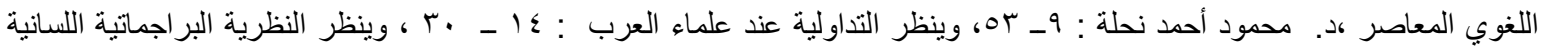

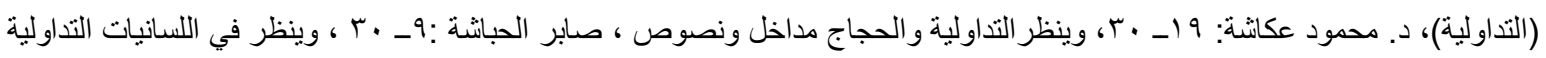

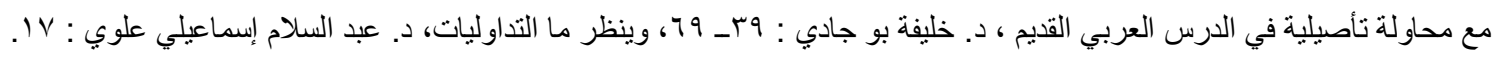

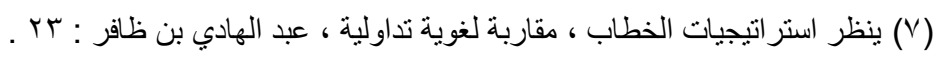

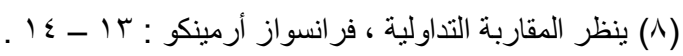

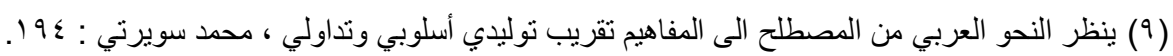

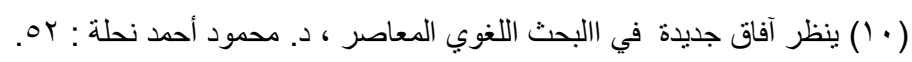

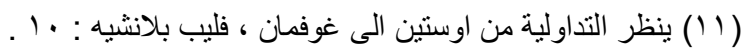

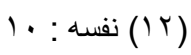

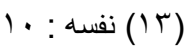

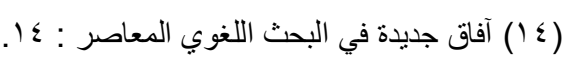

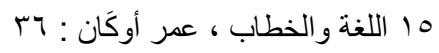

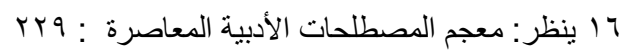

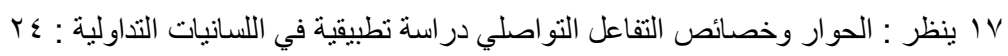

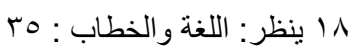

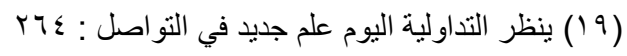

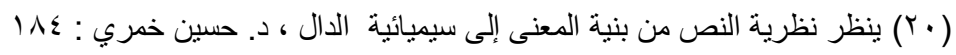

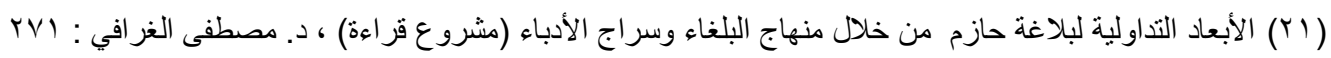

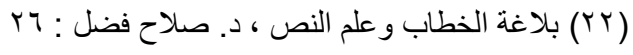

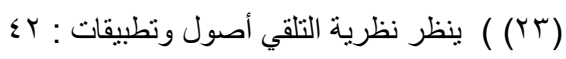

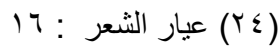

1 :

(T (Y) هذان المبدآن التداوليان أطلقتهما الباحثة روبين لاكوف في مقالتها ( منطق التأدب )، ينظر اللسان والميزان أو التكوثرالعقلي ، طه عبد

الرحمن : • • $90 \_91$ : عيار الثعر (YV) 


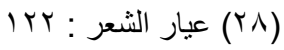

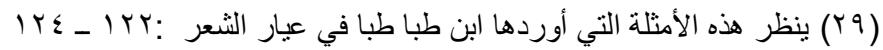
70 : 10

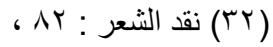

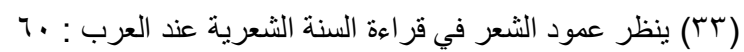

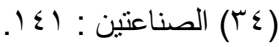

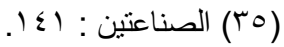

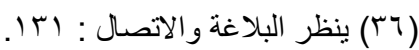

ro : ro (rV)

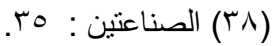

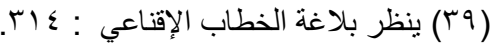

|نصأدو فأليراجي

ـ الأبعاد التداولية لبلاغة حازم من خلال منهاج البلغاء وسر اج الأدباء (مشروع قر اءة)، د. مصطفى الغر افي ، مجلة عالم الفكر ، المجلس

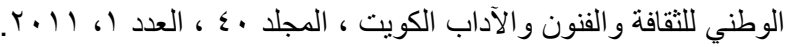

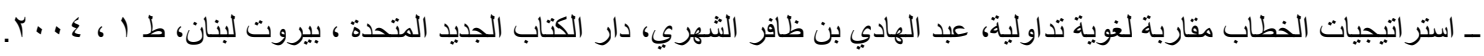

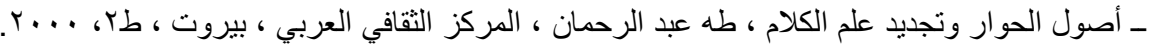

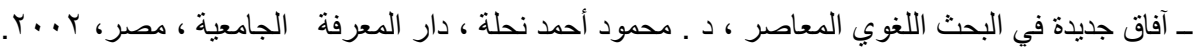

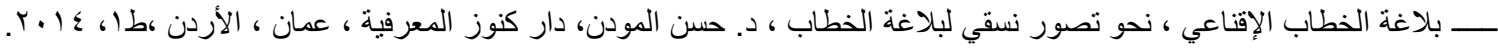

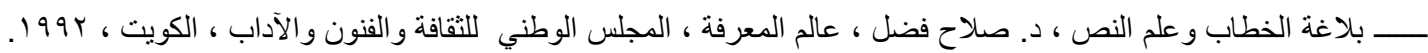

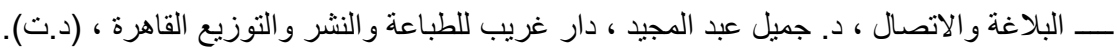

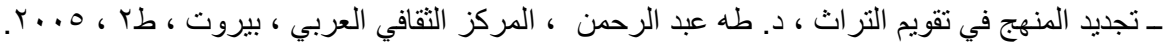

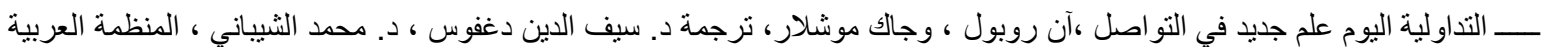

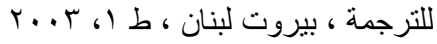
ــ التداولية عند العلماء العرب ، در اسة تداولية لظاهرة الأفعال الكلامية في التراث اللساني العربي ، د. مسعود صحر اوب ، دار الطليعة

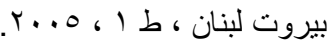
ـ التداولية من أوسنن إلى غوفمان ، فليب بلانشبه ، ترجمة صابر الحباثة ، عبد الرزاق الجمايعي ، عالم الكتب الحديث ،أربد الأردن ،طا ،

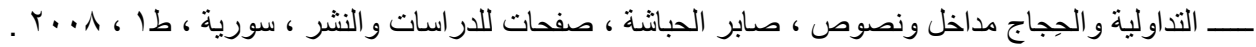

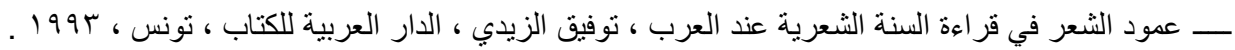

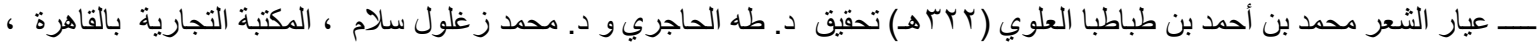
(b.د) 1907

بــــي اللسانيات التداولية مع محاولة تأصيلية في الدرس العربي القديم ، د. خليفة بوجادي ، بيت الحكمة للنشر و التوزيع الجزائر ، ط ب، لــــاب الصناعتين الكتابة والشعر أبو هلال العسكري (90بهـ) تحقيق علي محمد البجاوي ومحمد أبو الفضل ابر اهيم ، دار الفكر العربي ، بيروت ،ط |

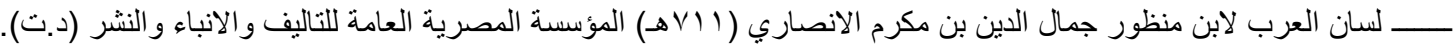

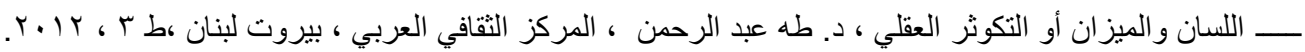

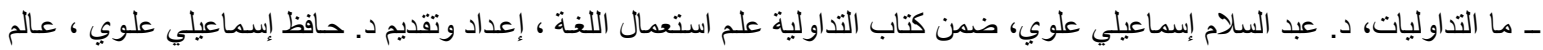

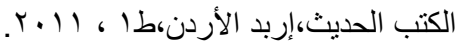


ــــالمقاربة التداولية ، فر انسواز أرمينكو، ترجمة د. سعيد علوش ، مركز الانماء القومي ، الرباط المغرب ، I9AV.

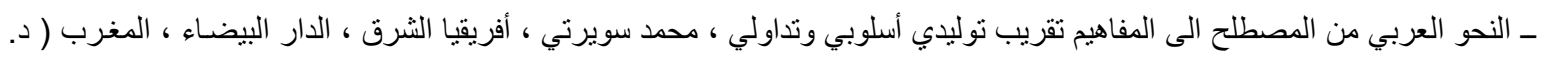
. Y...V (b

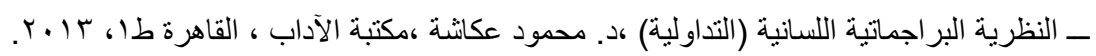

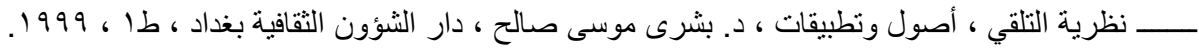

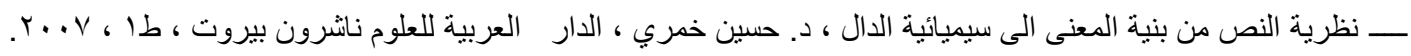

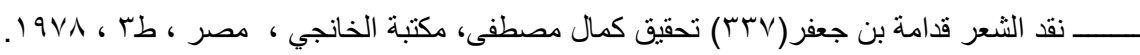

